\title{
Celestina: Documento bibliográfico (suplemento número 38)
}

\author{
Devid Paolini \\ The City College of New York
}

2406. ALBALÁ PELEGRÍN, Marta, "Gestures as a Transnational Language through Woodcuts: Celestina's Title Pages», Celestinesca 39 (2015), 79-112.

Un estudio del lenguaje corporal y de la gestualidad en las xilografías de las portadas de las ediciones más antiguas de LC. El análisis señala, entre otras cosas, como buena parte de estas representaciones iconográficas remite a la tradición del teatro y tenía como objetivo ayudar a los lectores a la comprensión del texto.

2407. ÁlVAREZ-MORENO, Raúl, "Casa, torre, árbol, muro: hacia una morfología del escenario urbano en las ediciones antiguas de Celestina», Celestinesca 39 (2015), 113-36.

Presenta un análisis morfológico de la representación del espacio urbano en los grabados de las primeras ediciones de $L C$, comparándolos con los de la edición alemana de Augsburgo, 1520. Trata, también, de las posibles fuentes (provenientes de diferentes campos artísticos) que los grabadores siguieron al preparar sus ilustraciones.

2408. ÁlVAREZ-MORENO, Raúl, "Celestina» según su lenguaje. Madrid: Editorial Pliegos. 2015. 472 pp. ISBN 978-84-96045-95-8.

"Celestina» según su lenguaje estudia el lenguaje en Celestina (14991502) como elemento primordial y no solo supletorio o subsiguiente de la contienda que tiene lugar en la obra. A causa del recorrido desde lo semántico a lo epistemológico y lo filosófico-mora -ética y política-, ya en el aristotelismo, el estoicismo o el cristianismo, el lenguaje, $y$ en particular las formas de entender el significado en pugna en el texto, se presentan como esenciales para entender las disputas y tensiones que lo articulan a todos los niveles. En estrecha relación con los cambios lingüísticos que tienen lugar en el siglo XV, la adscripción 
retórica de Celestina y, en concreto, la adopción de estrategias y técnicas escépticas se muestran determinantes en la crítica de los discursos dogmáticos del periodo y su verdad filosófico-intelectual sin salvarse como indiscutible y necesaria la cristiana que debía reemplazarla. Todo ello contribuiría en gran medida a la ambigüedad y a las distintas lecturas posibles ofrecidas por la obra [resumen del autor].

2409. ARDILA, J. A. G., "Génesis y conformación de la novela en España, 1499-1605", Ínsula 766 (2010), 8-11.

Trata de definir a nivel teórico qué es "novela» y habla luego de las principales obras que se escribieron en España desde LC hasta el Quijote.

2410. BARRIO OLANO, José Ignacio, "La Celestina y el Lazarillo en El manuscrito de piedra y El manuscrito de nieve, de Luis García Jambrina», Revista de Humanidades 28 (2016), 11-22.

Un análisis de las dos novelas históricas de García Jambrina mencionadas en el título y de la función de hipotexto que han tenido $L C$, el Lazarillo y El nombre de la rosa en su composición. Protagonista de las dos novelas es un joven detective, Fernando de Rojas, que tendrá que aclarar algunos crímenes acaecidos en la Salamanca de la época de los Reyes Católicos. Entre los personajes principales se cuentan también a Lázaro de Tormes y Celestina.

2411. BASTIANES, María, "La Celestina en escena (1909-2012)». Disertación doctoral, Universidad Complutense (Madrid), defendida el 20 de enero de 2106. Directores: Javier Huerta Calvo y Julio VélezSainz. 764pp.

Es una historia y análisis muy completo de $L C$ en las primeras escenificaciones sobre las tablas en España. Aunque cubre todas las adaptaciones, hay ocho que la autora trata en gran detalle y que demuestran el cambiante fondo socio-político español, captando también los gustos de los públicos en distintos momentos. Y son: Madrid, 1909 (Francisco Fernández Villegas); Madrid 1940 (Felipe Lluch); Madrid 1957 (Luis Escobar); Madrid 1965 (José Osuna); 1984 (Ángel Facio); Madrid 1988 (Adolfo Marsillach); Madrid-Barcelona 2004 (Robert Lepage); y Sevilla y en otras ciudades 2012 (Ricardo Iniesta). [Joseph T. Snow]

2412. BERNALDO DE QUIRÓS MATEO, José Antonio, «Sentencias y refranes en la hipotética Celestina primitiva», Tonos Digital 28.1 (2015), s.p. 
La premisa del presente trabajo es que el antiguo autor escribió los actos I-XIV de la obra maestra española y que Rojas la amplió y deturpó insertando sentencias traducidas del latín (de Aristóteles, Séneca y Petrarca). Un análisis comparativo entre estas últimas y las del antiguo autor pondría en evidencia la diferencia en la manera de utilizarlas y representaría una prueba más de las interpolaciones de Rojas al texto primitivo de $L C$. El artículo termina con un listado de las paremias que escribió el primer autor.

2413. BORSARI, Elisa y Héctor H. GASSÓ, «El martirio de Santa Apolonia entre la literatura y la iconografía», en De lo Humano a lo divino en la literatura medieval: santos, ángeles y demonios, ed. Juan Paredes. Granada: Universidad, 2012, 81-122.

Un detenido estudio de la figura y del martirio de Santa Apolonia y de su fortuna literaria e iconográfica. Si por un lado las obras castellanas medievales que tratan de la santa son muy escasas, numerosos son los testimonios de su representación visual. Se cita de paso a $L C$.

2414. BOTTA, Patrizia, "La Biblia en La Celestina», en La Biblia en el teatro español, coords. F. Domínguez Matito y J. A. Martínez Berbel. San Millán de la Cogolla: Academia del Hispanismo, 2012, 33-6.

Algunas reflexiones sobre la presencia de la Biblia en $L C$ con, al final, un listado de las citas (unas 70) y un breve análisis de estas (en qué actos se encuentran, cuáles personajes son más sentenciosos, qué libros de la Biblia se mencionan más, etc.).

2415. BROWN, Kenneth, «El acróstico de La Celestina: ¿ un artificio poético hispanohebreo?», eHumanista / Conversos 2 (2014), 54-85.

El estudio se enfoca en el acróstico de $L C$ y también en algunas citas textuales con el objetivo de demostrar lo que hay de claramente judaico en la obra.

2416. CANET VALLÉS, José Luis, «De nuevo sobre cajistas y correctores de las ediciones de la Comedia de Calisto y Melibea», Epos 30 (2014), 113-26.

Un detenido estudio de las variantes conjuntivas y separativas de los tres testimonios de la CCM conservados con el objetivo de determinar la relación y la dependencia entre ellos. Tras cuestionar la primacía del ejemplar burgalés (Fadrique de Basilea, ¿1499?), se señala que todas las comedias siguen, muy probablemente, un impreso perdido (Salamanca, 1500). 
2417. CULL, John, «Seeing with Sayings: The Visual Impact of Proverbs and Refrains in La Celestina», Celestinesca 39 (2015), 137-80.

El estudio se enfoca en los proverbios y paremias que se usan como acto perlocutivo y señala cómo estos presentarían, siempre, un importante referente visual y aludirían a un peligro inminente implícito o real. Se incluye al final un listado de los proverbios así como aparecen en $L C$ con al lado sus respectivas formas en los repertorios de la época.

2418. FERNÁNDEZ RIVERA, Enrique, «Las dos celestinas de Las galas del difunto de Valle-Inclán», Celestinesca 39 (2015), 181-96.

Un estudio de cómo la figura de Celestina ha ido recreándose en la mente y obra de diferentes autores analizando, en particular, los dos personajes celestinescos (una vieja que comparte algunas características con las meigas gallegas y una mujer dueña de un burdel) presentes en Las galas del difunto de Valle-Inclán.

2419. FERNÁNDEZ RIVERA, Enrique, «Introducción a: la cultura visual de La Celestina», Celestinesca 39 (2015), 77-8.

Algunas reflexiones sobre la cultura visual de LC y el estado actual de los estudios dedicados a este campo de investigación relativamente nuevo. Se señala, además, la inauguración de un nuevo portal dedicado a este asunto: <www.celestinavisual.org $>$.

2420. FERNÁNDEZ RIVERA, Enrique, "El cordón de Melibea y los remedios de amor en La Celestina», La corónica 42.1 (2013), 79-102.

Se presenta aquí una nueva interpretación de la simbología del cordón: según el autor todo el episodio sería una parodia de un remedio de amor de Bernardo de Gordonio. Este, de hecho, en un pasaje de su Lilio de medicina recomendaba que una vieja mostrara al enamorado un paño menstrual de la amada para que así la pudiera aborrecer y olvidar. El cordón/paño tiene una función, en $L C$, contraria: en vez de enfriar el deseo de Calisto lo aumenta todavía más.

2421. FRANZ, Thomas R., "Juan Valera and Juan Ruiz: The Reliance of Pepita Jiménez on the Libro de buen amor and LC", Decimonónica 10.2 (2013), 19-31.

Un estudio de las fuentes que Juan Valera siguió en su novela Pepita Jiménez (1874). Se cuentan no solo a $L C$ y la poesía mística, sino también, y sobre todo, el Libro de buen amor. 
2422. GARCÍA, Martha, Dialogismo teológico: "Devotio moderna», "Celestina» \& "Quijote». Vigo: Editorial Academia del Hispanismo, 2013. 194pp. ISBN 978-84-15175-71-1

En esta exegesis se procura divisar y releer el dialogismo explícito o implícito en la literatura medieval y áurea española con énfasis en la significancia de aquellos diálogos teológicos que resultan no tan perceptibles en la narrativa y en el teatro de la temprana Edad Moderna, no solo en el ámbito intratextual, sino también en el extratextual. Obviar el primero o ignorar el segundo podría obstaculizar, a corto y largo plazo, el valor estético y pragmático que radica en la paráfrasis de la teoría y en la glosa de la praxis que anida y sostiene las ciencias y humanidades [resumen de la autora].

Reseña: Por treze, tres, 17 de enero de 2016. Blog al cuidado de Juliette de Bertole. En línea: <https://portrezetres.wordpress. com/2016/01/17/review-dialogismo-teologico-devotio-moderna-celestina-quijote/\#more-3070> (fecha de consulta 1 de mayo de 2016).

2423. GARCÍA HERNÁNDEZ, Benjamín, Rosario LÓPEZ GREGORIS y Carmen GONZÁLEZ-VÁZQUEZ, "La recepción de Plauto y Terencio en la literatura española», en Ancient Comedy and Reception. Essays in Honor of Jeffrey Henderson, ed. S. Douglas Olson. Berlin/Boston: De Gruyter, 2014, 606-53.

Tras dedicar una primera parte a la considerable fortuna del Amphitruo y los Menaechmi, el ensayo se enfoca en la recepción de las comedias de Plauto y Terencio a lo largo de los siglos XV-XX. Entre las obras citadas aparece también $L C$, Celestina comentada y la celestinesca.

2424. GASTAÑAGA PONCE DE LEÓN, José Luis, "La Celestina, el humanismo vernáculo y la invención literaria», Celestinesca 39 (2015), 7-26.

Se analizan, en este artículo, algunas de las ideas típicas del humanismo vernáculo castellano que se desprenden de la carta prólogo y que relacionarían la obra maestra española con su probable ambiente de composición: la Salamanca de finales del siglo XV.

2425. GÓMEZ CANSECO, Luis, "El cuchillo de tu abuelo": en torno a la edición de un lugar oscuro en el auto I de La Celestina», Celestinesca 39 (2015), 27-38.

El autor está de acuerdo, en parte, con la lectura del pasaje que hizo Marciales, que a su vez se apoyó en un comentario de Kaspar von 
Barth: «cuchillo» sería en realidad una lectio facilior por "cuclillo», esto es, 'cornudo'. Sin embargo, Gómez Canseco piensa que no hace falta una emendatio ope ingenii: es suficiente leer la grafía <ch> de "cuchillo" como $/ \mathrm{k} /$ para obtener cuquillo, vocablo común en la época para referirse a los maridos de adúlteras.

2426. GÓMEZ-IVANOV, María Luisa, «El tahúr y la alcahueta, aliados de juegos prohibidos en Salamanca hacia 1497: Lucena, Repetición de amores y arte de axedrez», Celestinesca 39 (2015), 39-52.

Un artículo donde se conjetura sobre la existencia, en la Salamanca de finales del siglo XV, de una vieja Celestina experta en juegos de mesa clandestinos y amiga de Juan de Lucena. Tanto este último como Rojas habrían creado sus respectivas alcahuetas (más bien esbozada en la obra de Lucena) basándose en este personaje que, tal vez, de verdad tuvo su casa en «las tenerías, cabe el río».

2427. GUALANO, Andrea, Il plurilinguismo della prima traduzione italiana della "Celestina» (Roma, 1506), Tesis, Univesità di Torino, 2005-2006. (*)

2428. LAMPUGNANI, Raffaele, La prima traduzione italiana de "La Celestina». Primo commento linguistico e critico agli inizi del Cinquecento. Firenze: Leo Olschki, 2015. 172pp. ISBN 978-88-222-6423-7.

Un detenido estudio de la primera traducción italiana de $L C$, del estilo y actitud de su traductor y de sus posibles destinatarios. El análisis muestra el deseo del traductor de quedarse lo más posible fiel al original, su aguda sensibilidad hacia los problemas lingüísticos y sociolingüísticos, y una actitud crítica hacia los contenidos de la obra [traducción española del resumen en línea en la página: <www.olschki.it/ libro/9788822264237>].

Reseña: Esperienze letterarie 3.41 (2016), 148-50, Alfonso Ricca.

2429. LIZABE, Gladys, «La vejez en la literatura medieval española: miradas desde La Celestina», en Actas del XIII Congreso Internacional de la Asociación Hispánica de Literatura Medieval: In Memoriam Alan Deyermond, coords. J. M. Fradejas Rueda, D. A. Dietrick, M. J. Díez Garretas y D. Martín Sanz. Valladolid: Universidad, 2010, 2, 1131-46.

Analiza la visión de la vejez de Celestina, tanto la que se encuentra en los paratextos cuanto la que ofrecen los personajes de la obra. Por último, muestra la imagen de la vejez que la misma Celestina da frente a los demás (astuta con los criados, piadosa con los ricos, etc.). 
2430. LOBERA SERRANO, Francisco J., "La poesía de cancionero en LC: 'Oh, hideputa el trovador'», Revista de poética medieval 28 (2014), 225-43.

Un estudio de las canciones presentes en $L C$ y de las reacciones y comentarios que estas suscitan en los criados y Celestina. Todo esto con el objetivo de esclarecer la importancia de los cancioneros para la obra maestra española.

2431. LÓPEZ-RÍOS, Santiago, «Les images de l’Arabie dans la littérature espagnole du Moye Âge: lieux communs et préjugés dans le monde hispanique», en Parcourir le monde. Voyages d'Orient, ed. Dominique de Courcelles. París: École Nationale des Chartes, 2013, 75-88.

Trata de la doble percepción de Arabia en la literatura española medieval y renacentista (y que llega hasta nuestros días): por un lado aparece como un mundo fascinante, lleno de lujo y misterio; por el otro, como un lugar detestable, por la ignorancia y los prejuicios hacia ello y por ser la cuna de Mahoma y el Islam. Entre los textos analizados se encuentra también $L C$ : en el acto I Calisto afirma que los cabellos de Melibea son más lindos y resplandecen tanto como el oro de Arabia.

2432. LÓPEZ-RÍOS, Santiago, "La Celestina en el Franquismo: en torno a una frustrada película de José Luis Sáenz de Heredia», Acta literaria 49 (2014), 139-57.

Examina, basándose en documentación de archivo, el proyecto cinematográfico del director franquista José Luis Sáenz de Heredia de realizar una película sobre LC. El cineasta, al considerar los problemas que habría podido tener con la censura de la época, decidió al final abandonar la idea.

2433. MÉRIDA JIMÉNEZ, Rafael M., "Aviso al lector sobre la edición facsímil de la impresión alcalaína de 1575 de la Tragicomedia de Calisto y Melibea de Fernando de Rojas", en Tragicomedia de Calisto y Melibea, de Fernando de Rojas. Barcelona: Universitat, 2009, 7-26.

Es una introducción al facsímil de la edición de la TCM de 1575 que se conserva en la Biblioteca de la Universitat de Barcelona. Allí se habla de la fortuna de la obra a lo largo del siglo XVI y se enfoca en el estudio del ejemplar en cuestión tratando de su impresor, su composición, los pasajes censurados, su proveniencia y las notas que pueden rastrearse a lo largo de sus páginas. 
2434. MIAJA DE LA PEÑA, María Teresa, "De ocios y negocios en La Celestina», en Actas del XIII Congreso Internacional de la Asociación Hispánica de Literatura Medieval: In Memoriam Alan Deyermond, coords. J. M. Fradejas Rueda, D. A. Dietrick, M. J. Díez Garretas y D. Martín Sanz. Valladolid: Universidad, 2010, 2, 1373-82.

Se ocupa de las acciones y las actitudes de los personajes y sus diálogos mientras están en ocio o se están dedicando a algún negocio.

2435. MONTERO, Ana Isabel, "The Elusive Threshold: Textual and Sexual Transgression in the 1499(?) Edition of Celestina», eHumanista 30 (2015), 115-36.

El estudio señala la imposibilidad por parte de editores, críticos y traductores de imponer una lectura fija de LC. Como muestra el análisis de los grabados de la que supuestamente tendría que ser la más antigua edición de la CCM (Burgos, Fadrique de Basilea, ¿1499?), ni la obra ni tampoco el personaje mismo de la alcahueta pueden ser dominados o encasillados bajo una etiqueta específica.

2436. MONTERO, Ana Isabel, "Reading at the Threshold: The Role of Illustrations in the Reception of the Early Editions of Celestina», Celestinesca 39 (2015), 197-224.

Un análisis de los grabados de la Comedia de ¿Burgos, 1499? con el intento de esclarecer cómo los interpretaron los lectores y su influencia en las ediciones sucesivas.

2437. NAVARRO DURÁN, Rosa, "Metamorfosis de las lecturas en la creación literaria áurea: de La Celestina a San Juan de la Cruz», eHumanista 29 (2015), 290-306.

Se enfoca en LC, el Lazarillo de Tormes y algunas poesías de fray Luis de León y san Juan de la Cruz, con el objetivo de señalar algunas de las fuentes de los textos mencionados y mostrando, al mismo tiempo, la influencia que estos tuvieron en obras posteriores

2438. PAOLINI, Devid, "Celestina: documento bibliográfico (suplemento número 37)», Celestinesca 39 (2015), 67-74.

En el último suplemento bibliográfico se han agregado más de 30 entradas que desde 1985 suman ya 2405. 
2439. PARELLO, Vincent, "Cervantes y el género celestinesco: «Apercíbete, a la primera voz que oyeres, tomar calças de Villadiego» (Celestina, Auto XII, escena 3)», Anuario de estudios cervantinos 12 (2016), 325-39.

Un análisis de un refrán de $L C$ que es aprovechado por Cervantes en la primera décima de cabo roto de su Don Quijote con el objetivo, por un lado, de rendir un homenaje a la obra maestra española y, por el otro, de dar prueba de su gran inventiva.

2440. PEDROSA, José Manuel, "El ajuar de Centurio (Celestina 18), el Convite de Manrique y la Almoneda de Encina, con otras dotes, testamentos y disparates», eHumanista 31 (2015), 574-625.

Estudia el motivo literario y folclórico del inventario de bienes pobres, muy común en la literatura de disparate y del mundo al revés que todavía está presente hoy en día en la tradición oral panhispánica. Entre los numerosos textos y ejemplos analizados, hay también el acto XVIII de $L C$ con, en particular, la descripción que hace Centurio de su casa.

2441. PEDROSA, José Manuel, «La criada 'que hurtó la taça o perdió el anillo': Alfonso X, Fernando de Rojas, y Lope de Rueda», Criticón 113 (2011), 5-17.

Se analiza el tópico del criado que viene acusado, injustamente o no, de robar en casa de su amo o de perder alguna de sus pertenencias en la Cantiga 212 de Alfonso X, el acto IX de LC y el Décimo Paso (La generosa paliza) de Lope de Rueda. Se muestra, también, su pervivencia en obras modernas y contemporáneas de diferente índole (cuentos, ópera, cómics, películas, etc.).

2442. PINO MÁS, Dania del, «Paridades y conflictos: analogía de dos mundos en La Celestina de Teatro El Público», Celestinesca 39 (2015), 225-46.

Artículo que se enfoca en la adaptación de LC por la compañía cubana Teatro El Público llevada a las tablas en el año 2002. El espectáculo tuvo un éxito notable y su director supo encontrar el justo equilibrio entre el respeto del texto, con la eliminación de las partes más eruditas, por ejemplo, y la innovación y subversión, con la inclusión de elementos originales y un erotismo muy marcado que bien reflejaban la situación de la isla en aquel momento histórico determinado. 
2443. SAGUAR GARCÍA, Amaranta, "¡Hubo otra traducción quinientista de Celestina al italiano?», Celestinesca 39 (2015), 53-60.

En una de sus obras Pedro Simón Abril se refiere a una expresión de $L C$ traducida en italiano que no se encuentra en ninguna de las ediciones que hoy en día se conservan. Se conjetura entonces la posibilidad de que existiera otra versión al italiano en la época que no ha llegado hasta nosotros. Sin embargo, los datos a nuestra disposición parecen rechazar tal hipótesis.

2444. SAGUAR GARCÍA, Amaranta, «La desaparición de la traducción italiana de Celestina del mercado editorial en la segunda mitad del siglo XVI", en Grandes y pequeños de la literatura medieval y renacentista, ed. E. Blanco. Salamanca: SEMYR, 2016, 625-42.

Un detenido estudio de las características tipográficas de las diferentes ediciones de la traducción italiana de $L C$ con algunas reflexiones, al final, sobre la desaparición de la obra del mercado editorial italiano en la segunda mitad del Cinquecento.

2445. SAGUAR GARCÍA, Amaranta, "The Concept of Imago Agens in Celestina: Text and Image», Celestinesca 39 (2015), 247-74.

Estudia las imagenes agentes en $L C$ a través del análisis de algunos grabados que ilustran la muerte de los personajes principales y las descripciones que se hacen de esta. Termina valorando la importancia de la violencia, presente en la obra tanto a nivel textual cuanto visual, y su posible función didáctico-moral.

2446. SAGUAR GARCÍA, Amaranta, Intertextualidades bíblicas en "Celestina»: "devotio moderna» y humanismo cristiano. Vigo: Editorial Academia del Hispanismo, 2015. 238pp. ISBN 978-84-16187-11-9

De Celestina siempre se ha dicho que abunda en referencias bíblicas, sin embargo, poco o prácticamente nada se ha escrito sobre su procedencia. Este trabajo examina las posibles fuentes del conocimiento escriturario en Celestina y, descartada la Biblia, propone toda una serie de fuentes secundarias y terciarias a las que probablemente recurriera el autor. Asimismo, ubica estas fuentes dentro del contexto espiritual e intelectual de finales del siglo XV y principios del siglo XVI, poniendo de manifiesto cómo la relación de Celestina con la Biblia evidencia una gran deuda con el llamado Humanismo Cristiano [resumen de la autora]. 
2447. SALUS, Carol, Picasso and "Celestina»: The Artist's Vision of the Procuress. Newark, DE: Juan de la Cuesta Press, 2015. 151pp. 36 ilustraciones. ISBN 978-1-58871-251-6

Un detenido estudio del interés de Picasso por LC y de cómo el artista representó, recreó e interpretó, a través de diferentes medios y formas (grabados, aguafuertes, arcilla, también un poema, etc.) el personaje de la vieja alcahueta.

Reseña: Celestinesca 39 (2015), 61-6, Joseph T. Snow.

2448. SCHMIDT, Rachel, "Celestinas y majas en la obra de Goya, Alenza y Lucas Velázquez», Celestinesca 39 (2015), 275-328.

Estudia el desarrollo iconográfico de la figura de la prostituta en tres pintores del Siglo de las Luces: Francisco de Goya (1746-1828), Leonardo Alenza y Nieto (1807-1845) y Eugenio Lucas Velázquez (1817-1870).

2449. SCOTT, Rachel, "Nuevas sentencias sentía': Celestina and the Misery and Dignity of Man», Studia Aurea 8 (2014), 315-46.

El artículo se centra en los diferentes significados que la obra toma en base al momento y al contexto histórico en que se lee. En particular trata de la recepción de LC en los siglos XVI y XVII en Italia y España e intenta demostrar cómo su representación del conocimiento de sí mismo y de la soledad va más allá de sus raíces medievales para inscribirse, con derecho, en la historia del pensamiento renacentista de la miseria y dignidad del hombre.

2450. SNOW, Joseph T., "La metamorfosis de Celestina en el imaginario poético del siglo XVI: el caso de los testamentos», en Literatura y ficción: "estorias", aventuras y poesía en la Edad Media, Actas del Coloquio Internacional de la AHLM, coord. M. Haro Cortés. Valencia: Universitat, 2015, 2, 759-73.

Un estudio de las recreaciones poéticas del personaje de la alcahueta durante el siglo XVI que se centra, en particular, en tres textos anónimos: un testamento de 1582; un codicilo y una Carta a Silvia.

2451. SNOW, Joseph T., "Ilustrando Celestina en Celestinesca de 1977 a 2002: un catálogo", Celestinesca 39 (2015), 329-56.

Como dice el título, se presenta aquí un catálogo de las ilustraciones de LC que se reprodujeron en la revista Celestinesca desde 1977 hasta 2002. 
2452. TORREMOCHA HERNÁNDEZ, Margarita, «De la Celestina al alcahuete: del modelo literario a la realidad procesal», Tiempos modernos 30 (2015), s.p.

Un estudio sociológico e histórico de los diferentes tipos de alcahuetería que parte del análisis del arquetipo literario presente en la literatura del Siglo de Oro para llegar, a través del examen de documentos judiciales, a identificar dicho fenómeno en el mundo real de la época.

2453. TUSCANO, Pasquale, "Corrado Alvaro, lettore ed editore de La Celestina», en La traducción en las relaciones italo-españolas, ed. A. Camps. Barcelona: Universidad, 2012, 37-54.

Se centra en la traducción italiana de LC llevada a cabo por Corrado Alvaro en 1943. Se intentan determinar, en particular, las razones que empujaron el estudioso a acometer dicha tarea, estas son, la voluntad $y$ el deseo de llevar un aire nuevo en una cultura dominada todavía por el fascismo.

2454. VILLAGRÁ TERÁN, María Montserrat, «El tema de la magia en La Celestina», Atti dell'Accademia Peloritana dei Pericolanti LXXXII (2006), $111-46$.

En este estudio se revisa la cuestión de la magia en $L C$ mediante la consulta de estudios que han hecho la historia de la crítica celestinesca como el artículo de J. T. Snow: "Alisa, Melibea, Celestina y la magia» [vid. Celestinesca 23 (1999), núm. 1203 del suplemento]. Los resultados se rigen por una proyección a largo alcance del personaje de Melibea, personaje al que muy mal se adhiere -sobre todo a la luz de los tratados renacentistas- la etiqueta de "víctima de un embrujo». [resumen de la autora]

2455. VILLAGRÁ TERÁN, María Montserrat, «Un aspecto más sobre el problema del género en la literatura celestinesca: la presencia del tratado humanístico de tema femenino en algunas obras celestinescas", en Los géneros literarios desde el siglo XVI: Definición y transformación. Napoli: L'Orientale Editrice, 2008, 9-29.

En este estudio se analizan algunos aspectos del tratado humanístico de temática femenina presentes en la literatura celestinesca, sobre todo en $L C$ y en La Lozana andaluza. Entre esos aspectos se encuentra la forma de elocución predominante, la enumeración con valor intensificador y algunas características de los personajes femeninos propias de los estereotipos representativos de los tratados de la época. [resumen de la autora] 
2456. VILLAGRÁ TERÁN, María Montserrat, "El elemento mitificador en la génesis de los personajes celestinescos», Atti dell'Accademia Peloritana dei Pericolanti LXXXIV (2008), 65-76.

En este estudio se analizan dos de los aspectos temáticos más controvertidos de la literatura celestinesca centrados precisamente en los personajes femeninos de LC y de La Lozana andaluza: el ideal de perfección y el tema de la libertad que a veces se entiende como búsqueda de la autonomía con respecto al hombre. Ambos temas constituyen ese "elemento mitificador», tan importante para la configuración de los personajes femeninos celestinescos. [resumen de la autora]

2457. VILLAGRÁ TERÁN, María Montserrat, "El mito de Dafne y la Literatura celestinesca", Atti dell'Accademia Peloritana dei Pericolanti LXXXV (2009), 219-30.

Analiza el personaje de Lozana a la luz del mito de Dafne. La obra empieza con una clara referencia al mito cuando vemos a la hermosa Lozana que recibe una flecha de Cupido. Sin embargo, no conseguirá vivir plenamente su historia de amor con Diomedes, pues acabará en Roma, transformada no en laurel sino en una sifilítica prostituta. [resumen de la autora]

2458. VILLAGRÁ TERÁN, María Montserrat, "La literatura celestinesca y el debate lingüístico de principios del XVI", Atti dell'Accademia Peloritana dei Pericolanti LXXXVI (2010), 319-28.

Se enfoca en la lengua en La Lozana andaluza, no sin antes analizar la cuestión en LC. La conclusión a la que se llega es que en La Lozana, un uso de la lengua tan coloquial, forma parte de un intencionado juego paródico cuya finalidad es ridiculizar a esos ñoños tratados sobre mujeres perfectas y pías que tanto interesaron a los humanistas de la época. [resumen de la autora]

2459. VILLAGRÁ TERÁN, María Montserrat, "La literatura celestinesca en la clase de traducción: Estrategias didácticas destinadas a estudiantes italianos", en Actas del XVII Congreso Internacional de la AIH (Asociación Internacional de Hispanistas). Rumbos del hispanismo en el umbral del Cincuentenario de la AIH, eds. P. Botta y S. Pastor. Roma: Bagatto Libri, 2012, viII, 651-9.

Se presentan los resultados de un curso sobre traducción literaria que la autora impartió en la Universidad de Messina. Tras una discusión de las motivaciones y de los textos analizados ( $L C$ y La lozana andalu- 
$z a)$, se señalan la metodología y la didáctica empleadas para terminar con un balance conclusivo.

2460. VILLAGRÁ TERÁN, María Montserrat, «La recepción de lo celestinesco en La Cortigiana de Aretino", Atti dell'Accademia Peloritana dei Pericolanti LXX (1996), 397-431.

Estudia la relación formal y de contenido entre $L C$ y La Cortigiana de Pietro Aretino con el objetivo de determinar hasta qué punto la primera puede considerarse una de las fuentes de la obra del italiano. Los puntos en común señalados y analizados parecen no dejar espacio a ninguna duda: la obra maestra española, probablemente en su versión en 16 actos, fue sí uno de los textos que Aretino siguió al escribir su comedia.

2461. VILLAGRÁ TERÁN, María Montserrat, De mujeres, celestinas y damas. Los personajes de "La Celestina" a la luz de los géneros renacentistas. Messina: Armando Siciliano, 2012. 151pp. ISBN 978-88-74426-73-7

Un detenido estudio de los diferentes géneros relacionados con $L C$ (teatro, prosa didáctica, tratado, etc.) y de los personajes femeninos de la obra maestra española.

2462. VILLALOBOS GRAILLET, José Eduardo, "Análisis de las muertes en las adaptaciones de cine y televisión de $L C$ : convergencias y discrepancias con el texto original», eHumanista 34 (2016), 387-406.

Estudia las escenas de las muertes en las tres versiones cinematográficas (la de César Ardavín Fernández de 1969, Miguel Sabido de 1976 y Gerardo Vera de 1996) y las tres televisivas (la de Eduardo Fuller de 1967, Jesús Fernández Santos de 1974 y Juan Guerrero Zamora de 1983) de $L C$ disponibles hasta el momento con el objetivo de analizarlas y clasificarlas en adaptaciones cercanas, intermedias o alejadas, según las características de cada una.

2463. ZURDO RUIZ-AYÚCAR, M. ${ }^{a}$ I. Teresa, "Recursos aplicados para la transmisión del componente cultural en traducciones de $L C$ y del Quijote», Paremia 23 (2014), 35-44.

Un análisis de los problemas que surgen al traducir una paremia a otra lengua, sobre todo por su componente cultural. Se señalan y comentan, con el fin de determinar las estrategias empleadas, ejemplos concretos sacados de la traducción alemana, francesa e italiana, todas del siglo XVI, de $L C$ y de las versiones modernas al alemán, francés, italiano e inglés del Quijote. 